\title{
APPLICATION OF FUZZY AHP METHOD BASED ON EIGENVALUES FOR DECISION MAKING IN CONSTRUCTION INDUSTRY
}

\author{
Nataša Praščević, Živojin Praščević
}

Original scientific paper

The Analytic Hierarchy Process (AHP) has found wide application for multicriteria decision making (MCDM) in various areas. In the paper is given a short survey of the AHP application for decision making in the construction industry and realisation of construction projects. Authors have proposed a method based on the eigenvalue and eigenvector of the fuzzy comparison matrices for determination of local and global priorities of decision alternatives. These eigenvalues are determined using expected values of fuzzy numbers and their products. These fuzzy eigenvalues and eigenvectors are in further procedure applied for ranking the alternatives. Comparing the final ranks of alternatives, obtained according to proposed method and some other methods, the authors found good agreement. The fuzzy AHP, in comparison with AHP with crisp numbers, gives more complete, flexible and realistic results. A case study of the optimal selection of the structural system for a large industrial hall is presented in the paper.

Keywords: construction industry; fuzzy AHP; fuzzy number; multicriteria decision making

Primjena neizrazite AHP metode utemeljene na vlastitim vrijednostima za donošenje odluka u građevinarstvu

Izvorni znanstveni članak Analitički hijerarhijski proces (AHP) našao je široku primjenu za višekriterijsko donošenje odluka (MCDM) u različitim područjima. U radu je dan kratak osvrt na primjenu AHP metode za donošenje odluka u građevinarstvu i realizaciji građevinskih projekata. Autori su predložili metodu za određivanje vlastitih vrijednosti i vlastitih vektora neizrazitih (fuzzy) matrica komparacije za nalaženje lokalnih i globalnih prioriteta alternativa odlučivanja. Vlastite vrijednosti se određuju uporabom očekivane vrijednosti neizrazitih (fuzzy) brojeva i njihovih produkata. Dobivene vlastite vrijednosti i vlastiti vektori se u daljnjoj proceduri primjenjuju za rangiranje alternativa. Uspoređujući konačne rangove alternativa koji su dobiveni prema predloženoj metodi i nekim drugim metodama, autori su našli dobru suglasnost. AHP sa neizrazitim brojevima, u uspoređenju sa AHP sa izrazitim brojevima, daje kompletnije, fleksibilnije i realističnije rezultate. U radu je priložena studija slučaja optimalnog izbora konstruktivnog sustava jedne industrijske hale.

Ključne riječi: građevinarstvo; neizraziti AHP; neizraziti broj; višekriterijsko odlučivanje

\section{Introduction}

The Analytic Hierarchy Process (AHP) for choosing factors that are important for decision making (DM) was proposed by Saaty [1]. This is one of the useful methods in multi criteria decision making (MCDM), which has found wide application in many areas of science and practice, so there are a big number of references about AHP. In this process factors are selected and formulated in a hierarchy structure descending from one overall goal to criteria and alternatives, as it is shown in Fig. 1.

Each level may represent different factors (economical, technical, social, etc.) that are evaluated by experts. It provides an overall view of the complex relationships inherent in a considered situation. It helps the decision maker to assess whether the issues in each level have the same order of magnitude, so he can compare such homogeneous elements accurately. As Saaty [2] emphasises, "the most effective way to concentrate judgments is to take a pair of elements and compare them on a single property without concern for other properties or other elements".

Elements that have a global character are represented at the higher levels of the hierarchy. "The fundamental approach of AHP is to decompose a big problem into several smaller problems that are solved separately to determine their priority vectors. According to these values of the separate priority vectors, the final priority vector of the alternatives is calculated taking into account relationships between hierarchy levels" [2].

Unlike other methods of MCDM, here it is not necessary to know the exact numerical values of the factors being considered, so, it is enough to assess a good value of comparisons. This is important for application in the construction industry, where in the first phase of the construction project realization and preparation of preliminary feasibility studies, many important data concerning costs, time of works execution and others, are not precisely known, but the values of comparison of important factors could be better assessed. Since these values cannot be expressed precisely by the crisp numbers, it is necessary to use the fuzzy numbers. The usage of verbal judgements ("equal", "equal/moderate", "moderate" to "extreme") for mutual comparison of criteria, sub criteria and alternatives is more accurate than by integer or crisp numbers.

At each level, the comparisons may be expressed numerically or linguistically in words. These non numerical values are transformed to numerical ones according to the corresponding scale. According to Ishizaka [3] "the absence of units in comparison values is an important advantage, since these values are quotients of two quantities of the same kind". Application of fuzzy numbers instead of crisp numbers gives more realistic results and better ranking of alternatives.

The first solution of fuzzy AHP was proposed by Van Laarhoven and Pedrycz [4]. They used triangular fuzzy numbers and employed the logarithmic least squares method (LLSM) to generate elements of the priority vector (fuzzy weights). Buckley [5] used trapezoidal fuzzy numbers to express pair-wise comparison values. Csutora and Buckley [6] proposed "Lambda-Max method", which is direct fuzzification of the eigenvector method. Buckley et al. [7] revisited fuzzy hierarchical analysis and presented a new method of finding fuzzy weights by fuzzifying an equivalent method. They 
designed an evolutionary algorithm to estimate fuzzy weights. Wang and Chin [8] proposed an eigenvector method to generate interval or fuzzy weight estimate from an interval of fuzzy comparison matrix with trapezoidal and triangular fuzzy numbers, which differs from mentioned Lambda-Max method, proposed by Csutora and Buckley [6]. Mikhailov [9] developed a fuzzy programming method based on geometric representation of the prioritization process. The problem of finding elements of the priority vector is transformed into fuzzy programming problem.

The extent analysis, proposed by Chang [10], is used in many papers for handling the fuzzy AHP and ranking alternatives. He applied this approach with triangular fuzzy numbers [11] for calculation of the synthetic extent values $S_{i}$ of the pair-wise comparison matrix and using the principle of comparison of fuzzy numbers that was proposed in [10], found the requested weight vector of the comparison matrix.

In a number of papers for solving multicriteria decision problems, the AHP and fuzzy AHP are combined with the TOPSIS and Fuzzy TOPSIS method.

In this paper a method is proposed, which is different from methods proposed by other authors, for determination of fuzzy eigenvalues and fuzzy priority vectors based on expected values of fuzzy numbers. These fuzzy values are in further procedure used for ranking of alternatives.

\section{Application of AHP in construction}

Like in other industries, AHP as one of the methods of multicriteria decision making is used in the construction industry to solve many different problems, and here are emphasized some of them:

- Selection of construction projects for realization,

- Selection of a contractor for the project realization,

- Selection of temporary facilities and machinery in construction sites,

- Selection of construction methods,

- Choice of the maintenance strategy for the construction equipment,

- Choice of structural systems for design of bridges, buildings and other civil engineering projects,

- Choice of strategy for the maintenance of structural systems,

- Determination of weighting factors affecting safety on construction sites,

- Choice of a supplier of resources for construction,

- Ranking of real estates, etc.

\section{Non fuzzy AHP}

In the first Saaty's works is proposed and developed AHP with non fuzzy (crisp) data on several levels and many other authors have used this procedure to solve different problems of decision making. In this paper is considered the problem of multicriteria decision making in which given alternatives $A_{1}, A_{2}, \ldots, A_{m}$ are ranked for prescribed criteria $C_{1}, C_{2}, \ldots, C_{n}$. One model with three levels for solving these problems is shown in Fig. 1. Level 0 is related to the overall goal, which includes ranking of alternatives and determination of the best or most appropriate alternative. Level 1 encompasses prescribed criteria and level 2 contains alternatives that are related to these criteria.

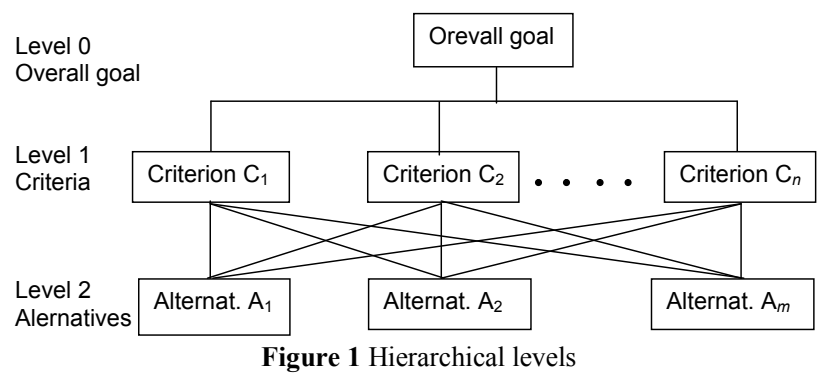

Unlike other methods of multicriteria decision making, relative weights $w_{i}$ of factors $F_{i}(i=1,2, \ldots, k)$, which in this case are criteria or alternatives, are compared in dependence on corresponding level. These weights are assessed usually by the decision making team. According to these values is determined the priority matrix $\boldsymbol{F}=\left[f_{i j}\right]_{k \times k}$, with elements

$f_{i j}=\frac{w_{i}}{w_{j}}, \quad i, j=1,2, \ldots k$,

where $w_{i}$ and $w_{j}$ are weights of corresponding criteria $C_{i}$ and $C_{j}$. This matrix is known as a reciprocal matrix, since it has positive entries everywhere and satisfies the reciprocal property

$f_{i j}=\frac{1}{f_{j i}}, f_{j i}>0, f_{i i}=1, \quad i, j=1,2, \ldots, k$.

This matrix is consistent, because the following conditions are satisfied

$f_{i j}=f_{i p} f_{p j}, \quad i, j=1,2, \ldots k ; \quad p=1,2, \ldots k$

According to Saaty [1, 2] necessary and sufficient condition for consistency is that the principal eigenvalue of matrix $\boldsymbol{F}$, for the eigenvalue problem

$\boldsymbol{F} \boldsymbol{w}=k \boldsymbol{w}$,

has value $\lambda_{\max }=k$.

For further analysis it is necessary to normalize vector $\boldsymbol{w}$ by dividing each of its elements by their sum

$\bar{w}_{i}=\frac{w_{i}}{w_{1}+w_{2}+\ldots w_{k}}, \quad i=1,2, \ldots, k$

The values $f_{i j}$, according to Saaty [1], [2], represent the pair-wise comparison or importance of the factor $F_{i}$ compared to the factor $F_{j}$ at a certain level of the hierarchy. Hence, matrix $\boldsymbol{F}$ is called pair-wise comparison matrix. As Saaty [1] emphasizes, in a general decision making it is impossible to give precise values of elements $f_{i j}$ according to Eq. (1), but only estimate them. For elicitation of pair-wise comparison judgments of criteria, he proposed fundamental scale of measurements. The 
differences $\Delta i j=f_{i j}-w_{i} / w_{j}$ cause inconsistency of the matrix $\boldsymbol{F}$, and its principal eigenvalue is

$\lambda_{\text {max }} \geq k$.

To every eigenvalue $\lambda_{i}$ corresponds eigenvector $\boldsymbol{w}_{i}$ that represents one solution of the system of $k$ homogeneous linear Eq. (3). Maximal positive real eigenvalue $\lambda_{\max }$ and the corresponding eigenvector $\boldsymbol{w}$ are accepted for further calculation. Since the estimated matrix $\boldsymbol{F}$ is not a consistent one, Saaty [1] introduced the consistency index $C I$ and the consistency ratio $C R$ for this matrix, that should be calculated by the following formulas

$$
\begin{aligned}
& C I=\frac{\lambda_{\max }-k}{k-1}, \\
& C R=\frac{C I}{R I} .
\end{aligned}
$$

$R I$ is called random consistency, which depends on the size of matrix $k$, and its values proposed by Saaty [1] are given in Tab. 1.

Table 1 Average random consistency $R$

\begin{tabular}{|l|c|c|c|c|c|c|c|c|c|c|}
\hline$K$ & 1 & 2 & 3 & 4 & 5 & 6 & 7 & 8 & 9 & 10 \\
\hline$R I$ & 0 & 0 & 0,58 & 0,90 & 1,12 & 1,24 & 1,32 & 1,41 & 1,45 & 1,49 \\
\hline
\end{tabular}

If $C R \leq 0,10$, the estimates of the elements of the vector $\boldsymbol{w}$ are acceptable. Otherwise, the consistency of the matrix $\boldsymbol{F}$ should be improved by changing values of some of its elements, taking into account that this matrix must be reciprocal. Saaty's method is based on calculation of the maximal eigenvalue and corresponding eigenvectors, and hence is known as the eigenvector method.

\section{$4 \quad$ Fuzzy AHP and determination of the priority vectors for ranking of alternatives}

Some of decision criteria are subjective and qualitative by nature, so the decision maker cannot easily express strengths of his preferences or provide exact pairwise comparison. Hence, the crisp numbers are not so suitable to express these pair-wise comparison values due to their vagueness. Since judgments of the decision maker or his team are uncertain and imprecise, it is much better to give pair-wise comparisons as fuzzy values than as crisp ones. As Wang et al. [8] emphasize, due to complexity and uncertainty involved in real world, sometimes, it is unrealistic or impossible to acquire exact judgments for these decision problems.

To overcome these shortcomings due to crisp numbers, the fuzzy AHP was developed for solving these problems of multicriteria decision making. The triangular and trapezoidal fuzzy numbers are commonly adoptive due to their simplicity in mathematical modelling of many problems in practice. In this paper are used triangular fuzzy numbers that are most frequently used by many authors.

The triangular fuzzy number, as a special type of a fuzzy set over the set of real numbers (real line) $R$, is shown in Fig. 2.

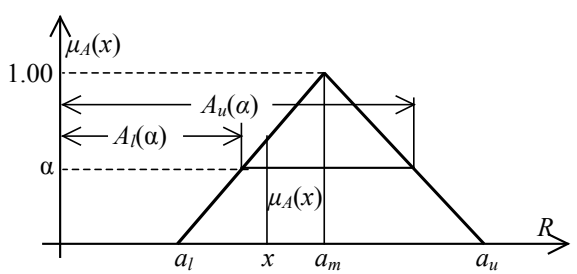

Figure 2 Triangular fuzzy number $\widetilde{A}$

Parametric presentation of a triangular fuzzy number $\widetilde{A}$ at level $\alpha$ is

$A_{\alpha}=\left[A_{l}(\alpha), A_{u}(\alpha)\right]$,

where

$A_{l}(\alpha)=a_{l}+\left(a_{m}-a_{l}\right) \alpha$
$A_{u}(\alpha)=a_{u}-\left(a_{u}-a_{m}\right) \alpha$
$0<\alpha \leq 1 \quad a_{l} \leq a_{m} \leq a_{u}$

Triangular fuzzy number is usually described by three characteristic values $a_{l}, a_{m}$ and $a_{u}$ which are crisp numbers

$\widetilde{A}=\left(a_{l}, a_{m}, a_{u}\right)$.

Reciprocal fuzzy number $\widetilde{A}^{-1}$ to $\widetilde{A}$ is for $a_{l}>0$

$\widetilde{A}^{-1}=\frac{1}{\widetilde{A}}=\left[\frac{1}{A_{u}(\alpha)}, \frac{1}{A_{l}(\alpha)}\right]$,

or approximatelly $[4,5,6]$

$\widetilde{A}^{-1}=\left(\frac{1}{a_{u}}, \frac{1}{a_{m}}, \frac{1}{a_{l}}\right)$.

since this fuzzy number is not exactly triangular one.

In this paper, the pair-wise comparison judgments, that express relative importance between factors $F_{i}$ and $F_{j}$ in the hierarchy, are expressed by the triangular fuzzy numbers $\widetilde{f}_{i j}$

$\widetilde{f}_{i j}=\left(f_{i j, l}, f_{i j, m}, f_{i j, u}\right), \quad \widetilde{f}_{i i}=(1,1,1) f_{i j, l}>0$

$i, j=1,2, \ldots, k, \quad i \neq j$,

which constitute a fuzzy comparison matrix $\widetilde{\boldsymbol{F}}$ with the following elements

$\widetilde{f}_{j i}=\frac{1}{\widetilde{f}_{i j}}=\left(\frac{1}{f_{i j, u}}, \frac{1}{f_{i j, m}}, \frac{1}{f_{i j, l}}\right), \quad i, j=1,2, \ldots, k, \quad i \neq j$.

This matrix is consistent if and only if [5]

$\widetilde{f}_{i p} \approx \widetilde{f}_{i p} \otimes \widetilde{f}_{p j}, \quad i, j=1,2, \ldots k, \quad p=1,2, \ldots k$

while the sign $\otimes$ denotes a fuzzy product. 
According to Eqs. $(10) \div(13)$ the fuzzy matrix $\widetilde{\boldsymbol{F}}$ can be expressed by three characteristic crisp matrices

$$
\widetilde{\boldsymbol{F}}=\left(\boldsymbol{F}_{l}, \boldsymbol{F}_{m}, \boldsymbol{F}_{u}\right) .
$$

Crisp matrices $\boldsymbol{F}_{l}, \boldsymbol{F}_{m}, \boldsymbol{F}_{u}$ are obtained according to (12) and (13) as follows

$$
\begin{aligned}
& \boldsymbol{F}_{l}=\left[\begin{array}{cccc}
1 & f_{12, l} & \ldots & f_{1 k, l} \\
1 / f_{12, u} & 1 & \ldots & f_{2 k, l} \\
\dot{\cdot} & \cdot & \cdots & \cdot \\
1 / f_{1 k, u} & 1 / f_{2 k, u} & \cdots & 1
\end{array}\right], \\
& \boldsymbol{F}_{m}=\left[\begin{array}{cccc}
1 & f_{12, m} & \cdots & f_{1 k, m} \\
1 / f_{12, m} & 1 & \cdots & f_{2 k, m} \\
\dot{1} & \cdot & \cdots & \cdot \\
1 / f_{1 k, m} & 1 / f_{2 k, m} & \cdots & 1
\end{array}\right], \\
& \boldsymbol{F}_{u}=\left[\begin{array}{cccc}
1 & f_{12, u} & \cdots & f_{1 k, u} \\
1 / f_{12, l} & 1 & \cdots & f_{2 k, u} \\
\dot{1} & \cdot & \cdots & \cdot \\
1 / f_{1 k, l} & 1 / f_{2 k, l} & \cdots & 1
\end{array}\right] \text {. }
\end{aligned}
$$

Buckley [5] has proved that fuzzy matrix $\tilde{\boldsymbol{F}}$ is consistent according to (15) if and only if its crisp matrix $\boldsymbol{F}_{m}$ is consistent.

Some authors have proposed triangular fuzzy numbers for expression of the intensity of importance on Saaty's absolute scale. In this paper the following fuzzy numbers are used

$$
\begin{aligned}
& \tilde{1}=\left(1,1, \gamma_{g}\right), \tilde{x}_{i}=\left(x_{i}-\gamma_{d}, x_{i}, x+\gamma_{g}\right) \text { for } \\
& 1<x_{i}<9, \widetilde{9}=\left(9-\gamma_{d}, 9,9\right) .
\end{aligned}
$$

where $\gamma_{d}$ and $\gamma_{g}$ are chosen real numbers.

The new technique for calibration of membership functions in the fuzzy AHP proposed by Ishizaka and Nguen [12] is very acceptable. The formula for definition of membership functions, given and used in this paper, is in accordance with that proposal.

\subsection{Approximate method for determining fuzzy weights}

Since Saaty's AHP method is based on finding eigenvalue and eigenvectors of the fuzzy matrix $\widetilde{\boldsymbol{F}}$ at the corresponding hierarchical level, here is proposed one method to solve the fuzzy eigenvalue and eigenvector problem and find solutions of the system of homogenous fuzzy linear equations

$$
\widetilde{\boldsymbol{F}} \otimes \widetilde{\boldsymbol{w}}=\tilde{\lambda}_{l} \otimes \widetilde{\boldsymbol{w}}
$$

where $\widetilde{\boldsymbol{F}}$ is the fuzzy reciprocal comparison matrix of type $[k \times k]$.

Elements of the fuzzy matrix $\widetilde{\boldsymbol{F}}$, fuzzy vector $\widetilde{\boldsymbol{w}}$ and fuzzy eigenvalue $\tilde{\lambda}$ are assumed as triangular fuzzy numbers, that may be denoted according to Eq. (10) as

$$
\widetilde{\boldsymbol{w}}=\left(\boldsymbol{w}_{l}, \boldsymbol{w}_{m}, \boldsymbol{w}_{u}\right), \quad \tilde{\lambda}=\left(\lambda_{l}, \lambda_{m}, \lambda_{u}\right)
$$

This method is based on the calculation of expected values of fuzzy numbers and their products. Expected value $E V(\tilde{A})$ of the fuzzy number $\widetilde{A}=\left(a_{l}, a_{m}, a_{u}\right)$, written in the parametric forms (9), is [13]

$E V(\widetilde{A})=\frac{a_{l}+2 a_{m}+a_{u}}{4}$.

The product of two positive fuzzy numbers $\widetilde{A} \otimes \widetilde{B}$, with $\quad \alpha$ cuts $A_{\alpha}=\left[A_{l}(\alpha), A_{u}(\alpha)\right] \quad$ and $B_{\alpha}=\left[B_{l}(\alpha), B_{u}(\alpha)\right] \quad 0<\alpha \leq 1$ can be written in the following form

$A_{\alpha} \otimes B_{\alpha}=\left[A_{l}(\alpha) B_{l}(\alpha), A_{u}(\alpha) B_{u}(\alpha)\right]$,

Expressing $A_{l}(\alpha), A_{u}(\alpha)$ in the form (9) by $a_{l}, a_{m}, a_{u}$ and $B_{l}(\alpha), B_{u}(\alpha)$ by $b_{l}, b_{m}, b_{u}$ for $a_{l}>0, b_{l}>0$, in a similar way, after integration, the expected value of the product of two fuzzy numbers is obtained

$$
\begin{aligned}
E V(\widetilde{A} \otimes \widetilde{B})= & \frac{1}{12}\left[\left(2 a_{l}+a_{m}\right) b_{l}+\right. \\
& \left.+\left(a_{l}+4 a_{m}+a_{u}\right) b_{m}+\left(a_{m}+2 a_{u}\right) b_{u}\right]
\end{aligned}
$$

A system of the fuzzy linear Eq. (18) may be written in the following form

$\widetilde{f}_{i 1} \otimes \widetilde{w}_{1} \oplus \widetilde{f}_{i 2} \otimes \widetilde{w}_{2} \oplus \ldots \oplus \tilde{f}_{i n} \otimes \widetilde{w}_{n}=\tilde{\lambda} \otimes \widetilde{w}_{i}, \quad i=1,2, \ldots . n$, where the sign $\oplus$ denotes the fuzzy addition.

The expected values of fuzzy products due to (22) are

$$
\begin{aligned}
& E V\left(\tilde{f}_{i j} \otimes \tilde{w}_{i j}\right)=\frac{1}{12}\left[\left(2 f_{i j, l}+f_{i j, m}\right) w_{j, l}+\right. \\
& \left.+\left(f_{i j, l}+4 f_{i j, m}+f_{i j, u}\right) w_{j, m}+\left(f_{i j, m}+2 f_{i j, u}\right) w_{j, u}\right] \\
& E V\left(\tilde{\lambda} \otimes \tilde{w}_{i}\right)=\frac{1}{12}\left[\left(2 \lambda_{l}+\lambda_{m}\right) w_{i, l}+\right. \\
& \left.+\left(\lambda_{l}+4 \lambda_{m}+\lambda_{u}\right) w_{i, m}+\left(\lambda_{m}+2 \lambda_{u}\right) w_{i, u}\right] \\
& \quad i, j=1,2, \ldots, k .
\end{aligned}
$$

The expected value of the sum of fuzzy numbers is equal to the sum of the expected values of fuzzy numbers

$\sum_{j=1}^{n} E V\left(\tilde{f}_{i j} \otimes \widetilde{w}_{j}\right)=\tilde{\lambda} \otimes \widetilde{w}_{i}, \quad i=1,2, \ldots, n$.

By introducing formulas for expected values of the fuzzy products (23) and (24) in these fuzzy equations, is obtained a system of fuzzy linear homogenous equations

$\overline{\boldsymbol{F}}_{l} \boldsymbol{w}_{l}+\overline{\boldsymbol{F}}_{m} \boldsymbol{w}_{m}+\overline{\boldsymbol{F}}_{u} \boldsymbol{w}_{u}-\bar{\lambda}_{l} \boldsymbol{w}_{l}-\lambda_{m} \boldsymbol{w}_{m}-\lambda_{u} \boldsymbol{w}_{u}=\mathbf{0}$

where are

$\overline{\boldsymbol{F}}_{l}=2 \boldsymbol{F}_{l}+\boldsymbol{F}_{m}, \overline{\boldsymbol{F}}_{m}=\boldsymbol{F}_{l}+4 \boldsymbol{F}_{m}+\boldsymbol{F}_{u}, \overline{\boldsymbol{F}}_{u}=\boldsymbol{F}_{m}+2 \boldsymbol{F}_{u}$, 


$$
\bar{\lambda}_{l}=2 \lambda_{l}+\lambda_{m}, \bar{\lambda}_{m}=\lambda_{l}+4 \lambda_{m}+\lambda_{u}, \bar{\lambda}_{u}=\lambda_{m}+2 \lambda_{u} .
$$

and vectors written in the transposed form

$$
\begin{aligned}
& \boldsymbol{w}_{l}=\left[w_{1, l}, w_{2, l}, \ldots, w_{n, l}\right]^{\mathrm{T}}, \\
& \boldsymbol{w}_{m}=\left[w_{1, m}, w_{2, m}, \ldots, w_{n, m}\right]^{\mathrm{T}}, \\
& \boldsymbol{w}_{u}=\left[w_{1, u}, w_{2, u}, \ldots, w_{n, u}\right]^{\mathrm{T}} .
\end{aligned}
$$

Since all the values in these equations are positive ones, the system of Eqs. (26) may be decomposed into three systems, which represent three crisp eigenvalue problems

$$
\overline{\boldsymbol{F}}_{l} \boldsymbol{w}_{l}=\bar{\lambda}_{l} \boldsymbol{w}_{l}, \overline{\boldsymbol{F}}_{m} \boldsymbol{w}_{m}=\overline{\boldsymbol{\lambda}}_{m} \boldsymbol{w}_{m}, \overline{\boldsymbol{F}}_{u} \boldsymbol{w}_{u}=\overline{\boldsymbol{\lambda}}_{u} \boldsymbol{w}_{u}
$$

By solving these three auxiliary eigenvalue problems, eigenvectors $\boldsymbol{w}_{l}, \boldsymbol{w}_{m}$ and $\boldsymbol{w}_{u}$ and auxiliary eigenvalues $\bar{\lambda}_{l}, \bar{\lambda}_{m}$ and $\bar{\lambda}_{u}$ are obtained. After that the requested eigenvalues $\lambda_{l}, \lambda_{m}$ and $\lambda_{u}$ are determined by solving the system of linear Eqs. (28).

To meet the requirements for the principal eigenvalues $\lambda_{l} \leq \lambda_{m} \leq \lambda_{u}$, normalised eigenvectors should satisfy the next condition

$\overline{\boldsymbol{w}}_{l} \leq \overline{\boldsymbol{w}}_{m} \leq \overline{\boldsymbol{w}}_{u}$.

The calculated eigenvectors $\boldsymbol{w}_{l}, \boldsymbol{w}_{m}$ and $\boldsymbol{w}_{u}$ should be normalized according to the following formulas

$$
\begin{aligned}
& \overline{\boldsymbol{w}}_{l}=\frac{\boldsymbol{w}_{l} \lambda_{l}}{s_{l} \lambda_{m}}, \\
& \overline{\boldsymbol{w}}_{l}=\frac{\boldsymbol{w}_{m}}{s_{m}}, \\
& \overline{\boldsymbol{w}}_{u}=\frac{\boldsymbol{w}_{u} \lambda_{u}}{s_{u} \lambda_{m}},
\end{aligned}
$$

where

$$
s_{l}=\sum_{i=1}^{n} w_{i, l}, \quad s_{m}=\sum_{i=1}^{n} w_{i, m}, \quad s_{u}=\sum_{i=1}^{n} w_{i, u} .
$$

\subsection{Steps in the execution of the fuzzy AHP}

Fuzzy AHP performs in several steps in a similar way as the procedure with crisp numbers, and is briefly explained here.

First step. Define the problem, overall goal that has to be attained, criteria, subcriteria, if necessary, and alternatives.

Second step. Define the hierarchy structure from the top level through intermediate levels that contains the criteria and subcriteria to the lowest level, which is related to the alternatives, as shown in Fig. 1.

Third step. Formulate the pair-wise comparison reciprocal fuzzy matrix $\widetilde{\boldsymbol{C}}$ for the criteria $C_{1}, C_{2}, \ldots, C_{n}$ by assessing the priority values as fuzzy numbers $\widetilde{c}_{i j}=\left(c_{i j, l}, c_{i j, m}, c_{i j, u}\right),(i, j=1,2, \ldots, n)$ using appropriate comparison scale adjusted to fuzzy values according to (17). Express the fuzzy matrix $\widetilde{\boldsymbol{C}}$ by three matrices $\boldsymbol{C}_{l}, \boldsymbol{C}_{m}$ and $\boldsymbol{C}_{u}$ according to (15) and (16). Solve the fuzzy eigenvalue problem $\widetilde{\boldsymbol{C}} \otimes \widetilde{\boldsymbol{w}}=\tilde{\lambda} \otimes \widetilde{\boldsymbol{w}}$, as described in the previous section, and determine the principal fuzzy eigenvalue $\tilde{\lambda}=\left(\lambda_{l}, \lambda_{m}, \lambda_{u}\right)$ and corresponding fuzzy eigenvectors $\widetilde{\boldsymbol{w}}=\left(\boldsymbol{w}_{l}, \boldsymbol{w}_{m}, \boldsymbol{w}_{u}\right)$. Normalize these vectors using formulas (32) and (33) to obtain the fuzzy priority vectors of criteria $\widetilde{\boldsymbol{w}}=\left(\overline{\boldsymbol{w}}_{l}, \overline{\boldsymbol{w}}_{m}, \overline{\boldsymbol{w}}_{u}\right)$.

For the matrix $\mathbf{C}_{m}$, calculate the consistency index $C I$ and consistency ratio $C R$ according to (6) and (7). If $C R \leq 0,10$, accept the assessed fuzzy elements of the pairwise matrix $\tilde{\boldsymbol{C}}$ and obtained eigenvalues and eigenvectors. If $C R>0,10$, improve the consistency of the matrix $\boldsymbol{C}_{m}$ by changing some of its elements and repeat the procedure until this condition is satisfied.

Fourth step. Formulate the pair-wise comparison matrices for the alternatives $\widetilde{\boldsymbol{A}}^{(j)}$ related to the criterion $C_{j}(j=1,2, \ldots, n)$

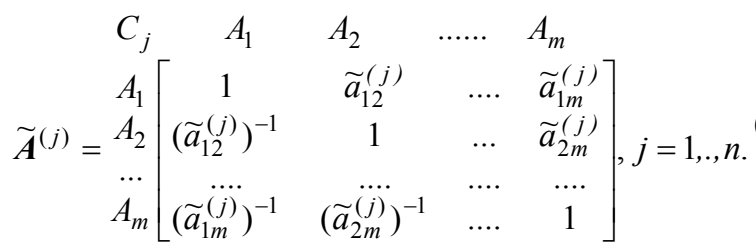

Express these fuzzy matrices by the matrices $\boldsymbol{A}_{l}^{(j)}, \boldsymbol{A}_{m}^{(j)}, \boldsymbol{A}_{u}^{(j)}$ according to (16). Solve the fuzzy eigenvalue problems

$$
\widetilde{\boldsymbol{A}}^{(j)} \otimes \widetilde{\boldsymbol{p}}^{(j)}=\widetilde{\lambda}^{(j)} \otimes \widetilde{\boldsymbol{p}}^{(j)}, j=1,2, \ldots, n
$$

to find the fuzzy principal eigenvalues $\tilde{\lambda}_{\max }^{(j)}=\left(\lambda_{l}^{(j)}, \lambda_{m}^{(j)}, \lambda_{u}^{(j)}\right) \quad$ and fuzzy eigenvectors $\widetilde{\boldsymbol{p}}_{\max }^{(j)}=\left(\boldsymbol{p}_{l}^{(j)}, \boldsymbol{p}_{m}^{(j)}, \boldsymbol{p}_{u}^{(j)}\right)$, consistency indices $C l^{(j)}$ and consistency ratios $C R^{(j)}$, according to (6) and (7) for matrices $\mathbf{A}_{m}^{(j)},(j=1,2, \ldots, n)$. If the consistency ratio is $C R^{(j)}>0,10$, change some of the assessed values $a_{i j, m}$ to obtain the satisfactory consistency of this matrix. Normalize vectors $\widetilde{\boldsymbol{p}}^{(j)}=\left(\boldsymbol{p}_{l}^{(j)}, \boldsymbol{p}_{m}^{(j)}, \boldsymbol{p}_{u}^{(j)}\right)$ by the formulas (32) and (33) to obtain normalized local priority vectors $\overline{\widetilde{\boldsymbol{p}}}^{(j)}=\left(\overline{\boldsymbol{p}}_{l}^{(j)}, \overline{\boldsymbol{p}}_{m}^{(j)}, \overline{\boldsymbol{p}}_{u}^{(j)}\right)$. This procedure is the same as in the step 3.

Fifth step. Formulate local priority fuzzy matrix $\overline{\widetilde{\boldsymbol{P}}}=\left(\overline{\boldsymbol{P}}_{l}, \overline{\boldsymbol{P}}_{m}, \overline{\boldsymbol{P}}_{u}\right)$, that contains normalized local priority vectors, where

$$
\begin{aligned}
& \overline{\boldsymbol{P}}_{l}=\left[\begin{array}{llll}
\overline{\boldsymbol{p}}_{l}^{(1)} & \overline{\boldsymbol{p}}_{l}^{(2)} & \ldots & \overline{\boldsymbol{p}}_{l}^{(n)}
\end{array}\right], \\
& \overline{\boldsymbol{P}}_{m}=\left[\begin{array}{llll}
\overline{\boldsymbol{p}}_{m}^{(1)} & \overline{\boldsymbol{p}}_{m}^{(2)} & \ldots & \overline{\boldsymbol{p}}_{m}^{(n)}
\end{array}\right], \\
& \overline{\boldsymbol{P}}_{u}=\left[\begin{array}{llll}
\overline{\boldsymbol{p}}_{u}^{(1)} & \overline{\boldsymbol{p}}_{u}^{(2)} & \ldots & \overline{\boldsymbol{p}}_{u}^{(n)}
\end{array}\right] .
\end{aligned}
$$


Multiply these matrices from the right by the priority vectors of the criteria respectively, which are determined in the third step

$$
\begin{aligned}
\overline{\boldsymbol{w}}_{l}^{\mathrm{T}} & =\left[\begin{array}{llll}
\bar{w}_{1, l} & \bar{w}_{2, l} & \ldots & \bar{w}_{n, l}
\end{array}\right]^{\mathrm{T}}, \\
\overline{\boldsymbol{w}}_{m}^{\mathrm{T}} & =\left[\begin{array}{llll}
\bar{w}_{1, m} & \bar{w}_{2, m} & \ldots & \bar{w}_{n, m}
\end{array}\right]^{\mathrm{T}}, \\
\overline{\boldsymbol{w}}_{u}^{\mathrm{T}} & =\left[\begin{array}{llll}
\bar{w}_{1, u} & \bar{w}_{2, u} & \ldots & \bar{w}_{n, u}
\end{array}\right]^{\mathrm{T}} .
\end{aligned}
$$

and obtain vectors of global priorities $\boldsymbol{g}_{l}, \boldsymbol{g}_{m}$ and $\boldsymbol{g}_{u}$

$$
\begin{aligned}
& \boldsymbol{g}_{l}=\boldsymbol{P}_{l} \overline{\boldsymbol{w}}_{l}=\left[\begin{array}{llll}
g_{1, l} & g_{2, l} & \ldots & g_{m, l}
\end{array}\right]^{\mathrm{T}} . \\
& \boldsymbol{g}_{m}=\boldsymbol{P}_{m} \overline{\boldsymbol{w}}_{m}=\left[\begin{array}{llll}
g_{1, m} & g_{2, m} & \ldots & g_{m, m}
\end{array}\right]^{\mathrm{T}} . \\
& \boldsymbol{g}_{u}=\boldsymbol{P}_{u} \overline{\boldsymbol{w}}_{u}=\left[\begin{array}{llll}
g_{1, u} & g_{2, u} & \cdots & g_{m, u}
\end{array}\right]^{\mathrm{T}} .
\end{aligned}
$$

These vectors constitute fuzzy matrix of global priorities $\widetilde{\boldsymbol{G}}=\left(\boldsymbol{g}_{l}, \boldsymbol{g}_{m}, \boldsymbol{g}_{u}\right)$ of alternatives $A_{1}, A_{2}, \ldots A_{m}$.

For every alternative $A_{i}(i=1,2, \ldots, m)$, elements of these vectors are expressed by the corresponding approximate triangular fuzzy numbers

$$
\tilde{g}_{i}=\left(g_{i . l}, g_{i, m}, g_{i, u}\right), \quad i=1,2, \ldots, m
$$

Sixth step. Alternatives $A_{i}(i=1,2, \ldots, m)$ are ranked in this step according to their global priorities that are expressed by triangular fuzzy numbers $\widetilde{g}_{i}(i=1,2, \ldots, m)$. More proposals for ranking fuzzy numbers exist in the literature, and here is used Lee and Le's[14] method improved by Cheng [15].

In this paper, comparison of the fuzzy numbers is based on the probability measure of fuzzy events, which was introduced by Zadeh [16]. The fuzzy numbers are ranked according to the generalized fuzzy mean (expected value) and generalized fuzzy spread (standard deviation). For the triangular probability distribution of the triangular fuzzy number as a fuzzy event, these values for the fuzzy number $\tilde{g}_{i}$ are calculated by the following formulas [15]:

- Generalized fuzzy mean (expected value)

$$
g_{i, e}=\frac{g_{i, l}+2 g_{i, m}+g_{i, u}}{4}, \quad i=1,2, \ldots, m
$$

- Generalized spread (standard deviation)

$$
\begin{aligned}
& \sigma_{i}=\left[\frac { 1 } { 8 0 } \left(3 g_{i, l}^{2}+4 g_{i, m}^{2}+3 g_{i, u}^{2}-4 g_{i, l} g_{i, m}-\right.\right. \\
& \left.\left.-2 g_{i, l} g_{i, u}-4 g_{i, m} g_{i, u}\right)\right]^{1 / 2}, i=1,2, \ldots, m .
\end{aligned}
$$

According to Lee and Li [14], a fuzzy number with a higher mean value and, at the same time, a lower spread is ranked better. However, it is not easy to compare two fuzzy numbers when one of them has a higher mean value and, at the same time, a higher spread and the other has a lower mean and, at the same time, a lower spread. Therefore, Cheng [15] proposed to rank fuzzy numbers according to the coefficient of variation $C V_{i}$

$$
C V_{i}=\frac{\sigma_{i}}{g_{i, e}}, \quad i=1,2, \ldots, m
$$

A fuzzy number or an alternative $A_{i}$ with a smaller $C V_{i}$ is ranked better, and the best ranked alternative $A^{*}$ is alternative $A_{i}$ with minimal $C V_{i}$.

According to this procedure, the authors have developed a corresponding computer program in MATLAB, which has been used to solve several problems of ranking alternatives in the construction industry. The recently proposed method and computer program have been used for making the optimal choice for the new railway trace in Montenegro, which is around $200 \mathrm{~km}$ long.

\section{$5 \quad$ Case study}

The proposed method of the fuzzy AHP was applied for the choice of the optimal structural reinforced concrete system of an industrial two-part hall with dimensions at the base of $2 \times 24,50 \mathrm{~m} \times 120,00 \mathrm{~m}$. This hall under construction is shown in Fig. 3. The choice of appropriate structural system and technology of construction, which affects costs and speed of construction, is one of main tasks of the design and construction team. The period of design and construction was limited on seven months, according to the contract between the investor and contractor.

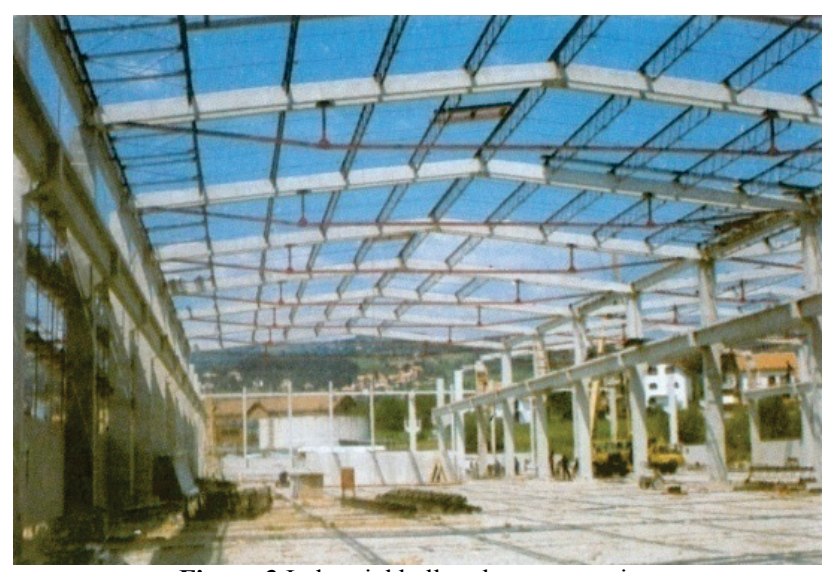

Figure 3 Industrial hall under construction

According to these requirements, the design team, in which the second author of this paper was included, established alternatives and criteria for the choice of the most acceptable structural system. For the choice of this system, the next three alternatives have been considered:

Alternative $A_{1}$ - Two chord reinforced concrete and steel girder supported by the reinforced concrete columns, shown in Fig. 1;

Alternative $A_{2}$ - Prestressed concrete girder supported by the reinforced concrete columns;

Alternative $A_{3}-$ Classical frame structure of reinforced concrete.

Four main criteria have been used:

$C_{1}$ - Summary costs of the design and the construction of the hall,

$C_{2}$ - Costs of annual maintenance of the hall,

$C_{3}$ - Time necessary for the construction works of the hall in weeks, 
$C_{4}$ - Technological possibilities of the contracting firm to construct this industrial hall in the chosen system.

These criteria are usually used as the most important in the construction industry for all civil engineering works, especially for this type of building. Besides these criteria, depending on the type and purpose of a building, often are taken into account the other criteria such as functional, aesthetical, environmental and so on.

The authors of this paper have assessed pair-wise comparison values on the basis of real technical, technological and financial data from this and similar projects and investments. According to the data, pair-wise comparison fuzzy matrices have been formulated:

Fuzzy matrix $\widetilde{\boldsymbol{C}}$ for the criteria

$$
\widetilde{\boldsymbol{C}}=\left[\begin{array}{ccc}
(1,1,1) & (1,1.5,2) & (1.5,2,2.5) \\
\left(\frac{1}{2}, \frac{1}{1.5}, 1\right) & (1,1,1) & (1,1,1.5) \\
\left(\frac{1}{2.5}, \frac{1}{2}, \frac{1}{1.5}\right) & \left(\frac{1}{1.5}, 1,1\right) & (1,1,1) \\
\left(\frac{1}{3}, \frac{1}{2.5}, \frac{1}{2}\right) & \left(\frac{1}{2}, \frac{1}{1.5}, 1\right) & \left(\frac{1}{2}, \frac{1}{1.5}, 1\right)
\end{array}\right.
$$

Fuzzy matrices $\widetilde{\boldsymbol{A}}^{(j)}$ related to the criterion $C_{j}(j=1$, $2,3,4)$ are

$$
\begin{aligned}
& \widetilde{\boldsymbol{A}}^{(1)}=\left[\begin{array}{ccc}
(1,1,1) & (1.2,1.5,1.8) & (1.7,2,2.3) \\
\left(\frac{1}{1.8}, \frac{1}{1.5}, \frac{1}{1.2}\right) & (1,1,1) & (1.2,1.5,1.8) \\
\left(\frac{1}{2.3}, \frac{1}{2}, \frac{1}{1.7}\right) & \left(\frac{1}{1.8}, \frac{1}{1.5}, \frac{1}{1.2}\right) & (1,1,1)
\end{array}\right], \\
& \widetilde{\boldsymbol{A}}^{(2)}=\left[\begin{array}{ccc}
\left(\frac{1}{1.6}, \frac{1}{1.3}, 1\right) & (1,1,1) & (0.9,1.2,1.5) \\
\left(\frac{1}{1.8}, \frac{1}{1.5}, \frac{1}{1.2}\right) & \left(\frac{1}{1.5}, \frac{1}{1.2}, \frac{1}{0.9}\right) & (1,1,1)
\end{array}\right], \\
& \widetilde{\boldsymbol{A}}^{(3)}=\left[\begin{array}{ccc}
(1.1,1) & (1,1.3,1.6) & (1.2,1.5,1.8) \\
\left(\frac{1}{1.5}, \frac{1}{1.2}, \frac{1}{0.9}\right) & (1,1,1) & (1.1,1.4,1.7) \\
\left(\frac{1}{1.8}, \frac{1}{1.5}, \frac{1}{1.2}\right) & \left(\frac{1}{1.7}, \frac{1}{1.4}, \frac{1}{1.1}\right) & (1,1,1)
\end{array}\right], \\
& {\left[\begin{array}{ccc}
(1,1,1) & (1,1.3,1.6) & (0.9,1.2,1.5) \\
\left(\frac{1}{1.6}, \frac{1}{1.3}, 1\right) & (1,1,1) & (0.9,1.2,1.5) \\
\left(\frac{1}{1.5}, \frac{1}{1.2}, \frac{1}{0.9}\right) & \left(\frac{1}{1.5}, \frac{1}{1.2}, \frac{1}{0.9}\right) & (1,1,1)
\end{array}\right] .}
\end{aligned}
$$

Elements of the comparison matrices are expressed by the proposed formula (16) with $\gamma_{d}=\gamma_{g}=0,5$ for elements of matrix $\widetilde{\boldsymbol{C}}$ and $\gamma_{d}=\gamma_{g}=0,3$ for matrices $\widetilde{\boldsymbol{A}}^{(j)}, j=1,2,3,4$.

Applying the mentioned computer program, the following principal eigenvalues for the matrix $\widetilde{C}$ and normalised eigenvectors are obtained $\lambda_{l}=3,3663, \lambda_{m}=4,0075, \lambda_{u}=5,1464$,

$$
\begin{aligned}
& \overline{\boldsymbol{w}}_{l}=\left[\begin{array}{llll}
0,3211 & 0,2007 & 0,1898 & 0,1283
\end{array}\right], \\
& \overline{\boldsymbol{w}}_{m}=\left[\begin{array}{llll}
0,3845 & 0,2391 & 0,2222 & 0,1541
\end{array}\right], \\
& \overline{\boldsymbol{w}}_{u}=\left[\begin{array}{llll}
0,4820 & 0,3135 & 0,2872 & 0,2015
\end{array}\right] .
\end{aligned}
$$

For the matrix $\boldsymbol{C}_{m}$ are found consistency index $C I=$ 0,0025 and consistency ratio $C R=0,0028<0,10$.

Since the consistency index and consistency ratio are very small, the assessed matrix $\widetilde{\boldsymbol{C}}$ is very consistent and may be accepted.

For matrices $\boldsymbol{A}^{(j)}$ of alternatives $A_{i}(i=1,2,3)$ related to the criteria $C_{j}, \quad(j=1,2,3,4)$ the following results have been obtained:

Principal eigenvalues are given in Tab. 2 .

\begin{tabular}{|c|c|c|c|} 
Table 2 Principal eigenvectors \\
\begin{tabular}{|c|c|c|c|}
\hline Matrix $\widetilde{\boldsymbol{A}}^{(j)}$ & $\lambda_{l}^{(j)}$ & $\lambda_{m}^{(j)}$ & $\lambda_{u}^{(j)}$ \\
\hline$\widetilde{\boldsymbol{A}}^{(1)}$ & 2,6627 & 3,0015 & 3,4097 \\
\hline$\widetilde{\boldsymbol{A}}^{(2)}$ & 2,6880 & 3,0002 & 3,5207 \\
\hline$\widetilde{\boldsymbol{A}}^{(3)}$ & 2,5978 & 3,0015 & 3,5071 \\
\hline$\widetilde{\boldsymbol{A}}^{(4)}$ & 2,5604 & 3,0013 & 3,5654 \\
\hline
\end{tabular}
\end{tabular}

Since the principal eigenvalue of matrices $\boldsymbol{A}_{m}^{(j)},(j=1$, $2,3,4)$ are very close to the number of their columns $n=$ 3 , these matrices are consistent ones.

Priority fuzzy matrices, $\boldsymbol{P}_{l}, \boldsymbol{P}_{m}$ and $\boldsymbol{P}_{u}$, that contain normalized eigenvectors (local priority vectors) according to (36) are

$$
\begin{aligned}
& \overline{\boldsymbol{P}}_{l}=\left[\begin{array}{llll}
0,4073 & 0,3525 & 0,3415 & 0,3242 \\
0,2813 & 0,2742 & 0,2985 & 0,2470 \\
0,1986 & 0,2359 & 0,2254 & 0,2818
\end{array}\right], \\
& \overline{\boldsymbol{P}}_{m}=\left[\begin{array}{llll}
0,4586 & 0,4082 & 0,3968 & 0,3814 \\
0,3194 & 0,3201 & 0,3459 & 0,2874 \\
0,2220 & 0,2718 & 0,2573 & 0,3312
\end{array}\right], \\
& \overline{\boldsymbol{P}}_{u}=\left[\begin{array}{llll}
0,5178 & 0,4742 & 0,4617 & 0,4494 \\
0,3658 & 0,3781 & 0,4065 & 0,3437 \\
0,2524 & 0,3212 & 0,3003 & 0,3949
\end{array}\right] .
\end{aligned}
$$

Vectors of global priorities $\boldsymbol{g}_{l}, \boldsymbol{g}_{m}$ and $\boldsymbol{g}_{u}$ are calculated according to the expression (38), multiplying matrices $\overline{\boldsymbol{P}}_{l}, \quad \overline{\boldsymbol{P}}_{m}$ and $\overline{\boldsymbol{P}}_{u}$ by normalised vectors $\overline{\boldsymbol{w}}_{l}, \overline{\boldsymbol{w}}_{m}$ and $\overline{\boldsymbol{w}}_{u}$ respectively, and results are shown in Tab. 3. For each alternative components of these vectors form fuzzy numbers $\widetilde{g}_{i}=\left(g_{i, l}, g_{i, m}, g_{i, u}\right)(i=1,2,3)$. For these fuzzy numbers, generalized fuzzy means (expected values), standard deviations (spreads) and coefficients of variations $V_{i}$ are determined for alternatives $A_{i}(i=1,2,3)$ using the expressions (40), (41) and (42). The alternatives are ranked according to these values and the results are shown in Tab. 4.

According to Chang's method based on the extent analysis [11] priority normalized vector of alternatives $\overline{\boldsymbol{d}}=\left[\begin{array}{lll}0,5165 & 0,3194 & 0,1641\end{array}\right]^{\mathrm{T}}$ is obtained. Alternative with higher component of this vector is better ranked.

Alternative $A_{1}$ is the best ranked according to the expected value $g_{1, e}=0,443$ and the coefficient of 
variation $V_{1}=11,41 \%$. This alternative has a discernible advantage over the other alternatives. This problem has been solved by the authors using the modified fuzzy TOPSIS method [17] and the same order of alternatives is obtained.

Table 3 Vectors of global priorities, expected values and standard deviations

\begin{tabular}{|c|c|c|c|c|c|}
\hline Alternative & $\begin{array}{c}\text { Vector } \\
\boldsymbol{g}_{l}\end{array}$ & $\begin{array}{c}\text { Vector } \\
\boldsymbol{g}_{m}\end{array}$ & $\begin{array}{c}\text { Vector } \\
\boldsymbol{g}_{u}\end{array}$ & $\begin{array}{c}\text { Exp. val. } \\
g_{i, e}\end{array}$ & $\begin{array}{c}\text { Stand. } \\
\text { dev. (\%) }\end{array}$ \\
\hline$A_{1}$ & 0,308 & 0,421 & 0,621 & 0,443 & 11,41 \\
\hline$A_{2}$ & 0,106 & 0,195 & 0,442 & 0,235 & 11,71 \\
\hline$A_{3}$ & 0,120 & 0,245 & 0,575 & 0,297 & 11,78 \\
\hline
\end{tabular}

\begin{tabular}{|c|c|c|c|c|c|}
\hline $\begin{array}{c}\text { Rank } \\
\text { of } \\
\text { alter. }\end{array}$ & Alternative & $\begin{array}{c}\text { Exp. } \\
\text { value } \\
g_{i, e} \\
\end{array}$ & Alternative & $\begin{array}{c}\text { Coeffic. } V_{i} \\
(\%) \\
(\text { Cheng) }\end{array}$ & $\begin{array}{l}\text { Ranking } \\
\text { vector } \boldsymbol{d} \\
\text { (Chang) }\end{array}$ \\
\hline 1 & $A_{1}=A^{*}$ & 0,443 & $A_{1}=A^{*}$ & 11,41 & 0,5165 \\
\hline 2 & $A_{2}$ & 0,339 & $A_{3}$ & 11,71 & 0,3194 \\
\hline 3 & $A_{3}$ & 0,274 & $A_{2}$ & 11,78 & 0,1641 \\
\hline
\end{tabular}

The alternative of the structural system $A_{1}$ has been chosen for realization and the hall has been successfully finished in the planned and contracted time between the investor and contractor.

\section{Conclusions}

The fuzzy AHP is one of very useful methods for multicriteria decision making (MCDM) in which the factors that affect the decision making (criteria, subcriteria and alternatives) are hierarchically arranged descending from one overall goal to the criteria, subcriteria and alternatives in successive levels. In this process, at all levels, these factors are mutually compared and these comparisons are expressed numerically or linguistically in words which are further transformed into numbers according to the given comparison scale.

This method, as other methods of MCDM, found useful applications in the construction industry and construction project management as a help for rational decision making, so a large number of references in this field exists in the literature.

The fuzzy AHP method gives more complete, flexible and realistic results, especially for the decision criteria that have qualitative nature. The procedure for determination of approximate eigenvalues and eigenvectors of the reciprocal matrices, proposed in this paper, is used to find priority vectors for alternatives. This procedure and corresponding computer program have been used several times for choosing most appropriate alternative for realisation of some construction projects. Comparisons that authors have made with application of some other methods of MCDM, have shown good accordance with results obtained by the fuzzy AHP. In many situations, especially when number of alternatives is large, it is advisable to combine fuzzy AHP with other methods of MCDM, using AHP for determinations of the criteria weights and after that chose the method for ranking alternatives like TOPSIS, VICOR or some other method for ranking alternatives for multicriteria decision making.

\section{References}

[1] Saaty, T. L. The Analytic hierarchy Process. McGraw-Hill, New York, 1980.

[2] Saaty, T. L. How to make a decision: Analytic Hierarchy Process. // European Journal of Operational Research. 48, (1990), pp. 9-26. DOI: 10.1016/0377-2217(90)90057-I

[3] Ishizaka, A. Clusters and Pivots for Evaluating a Large Number of Alternatives in AHP, SOBRAPO, Brazilian Operational Research Society, 2012. URL: www.scielo.br/pope.

[4] Van Laarhoven, P. J. M.; Pedrycz, W. A fuzzy extension of Saaty's priority theory. // Fuzzy Sets and Systems. 11, (1983), pp. 229-241. DOI: 10.1016/S0165-0114(83)80082-7

[5] Buckley, J. J. Fuzzy hierarchical analysis. // Fuzzy Sets and Systems. 17, (1985), pp. 233-247. DOI: 10.1016/01650114(85)90090-9

[6] Csutora, R.; Buckley, J. J. Fuzzy hierarchical analysis: the Lambda-Max method. // Fuzzy Sets and Systems. 120, (2001) pp. 181-195. DOI: 10.1016/S0165-0114(99)00155-4

[7] Buckley, J. J.; Feuring, T.; Hayashi, Y. Fuzzy hierarchical analysis revisited. // European Journal of Operational Research. 129, (2001), pp. 48-64. DOI: 10.1016/S03772217(99)00405-1

[8] Wang, J. M., Chin, K-S., An eigenvector method for generalizing normalized interval and fuzzy weights. // Applied Mathematics and Computation, 181, (2006), pp. 1257-1275. DOI: 10.1016/j.amc.2006.02.026

[9] Mikhailov, L. A fuzzy programming method for deriving priorities in analytic hierarchy process. // Journal of the Operational Research Society. 51, (2000), pp. 341-349. DOI: 10.1057/palgrave.jors.2600899

[10] Chang, D.-Y.; Extent Analysis and Synthetic Decision, Optimization Techniques and Applications. Vol. 1, World scientific, Singapore, 1992.

[11] Chang, D.-Y. Application of the extent analysis method on fuzzy AHP. // European Journal of Operational Research, 95, 12(1996), pp. 649-655. DOI: 10.1016/0377-2217(95)003002

[12] Ishizaka, A.; Nguyen, N. H. Calibrated fuzzy AHP for current bank account selection. // Expert systems with applications. 40, (2013), pp. 3775-3783. DOl: 10.1016/j.eswa.2012.12.089

[13] Chanas, S. On the interval approximation fuzzy numbers. // Fuzzy Sets and Systems. 122, (2001), pp. 353-356. DOI: 10.1016/S0165-0114(00)00080-4

[14] Lee, E. S.; Li, R. L. Comparison of fuzzy numbers based on the probability measure of fuzzy events. // Comput. Mathematic Application. 15, (1988), pp. 887-896. DOI: 10.1016/0898-1221(88)90124-1

[15] Cheng, C-H. A new approach for ranking fuzzy numbers by distance method. // Fuzzy Sets and Systems, 95, (1992), pp. 307-317. DOI: 10.1016/S0165-0114(96)00272-2

[16] Zadeh, L. A. Probability measures of fuzzy events. // Journal of Mathematic Analysis and Applications. 23, (1968), pp. 421-427. DOI: 10.1016/0022-247X(68)90078-4

[17] Prascevic, Z.; Prascevic, N. One modification of fuzzy TOPSIS method. // Journal of Modelling in Management. 8, (2013), pp. 81-102. DOI: 10.1108/17465661311311996

\section{Authors' addresses}

Doc. dr. sc. Nataša Praščević, dipl. ing .grad.

Prof. dr. sc. Živojin Praščević, dipl. ing. građ.

University of Belgrade, Faculty of Civil Engineering Bulevar kralja Aleksandra 73, 11120 Belgrade, Serbia E-mail: natasa@grf.bg.ac.rs

E-mail: zika@grf.bg.ac.rs 